\title{
Razões para a prática de ginásticas de academia como actividade de lazer
}

\author{
Ana L. Pereira \\ Faculdade de Ciências do Desporto e de Educação Física \\ Universidade do Porto \\ Portugal
}

\section{RESUMO}

O tempo livre, é um tempo "ganho", se ocupado de uma forma útil e rentabilizado enquanto capital. Na diversidade de actividades de lazer e tempo livre, a actividade física surge como uma das formas de "concorrência» à crescente tecnologização da nossa sociedade. Verifica-se, por isso, um aumento do número de ginásios/academias/health-clubs para assim corresponder às necessidades evidenciadas de uma prática de actividade física.

O presente estudo tem como principal objectivo, analisar e conhecer o aluno/cliente dos ginásios/academias/health-clubs da cidade do Porto, através da percepção do sentido da escolha da actividade e da importância que a esta confere. Na sua concretização desenvolveu-se uma pesquisa no terreno, complementada por entrevistas semiabertas a alunos/clientes destes locais. A análise dos resultados do nosso estudo sugerem que o cliente do ginásio/academia/health-club opta por este tipo de actividade, pela necessidade de prática de actividade física e por considerar que é esta que melhor lhe permite corresponder aos parâmetros estético-corporais da nossa sociedade. Além disso, parecem ser estas práticas as que mais se adequam às dificuldades inerentes aos constrangimentos laborais. A frequência com que se desloca a estes locais depende dos objectivos intrínsecos à prática de uma actividade física, assim como das relações sociais que aí se vão estabelecendo.

Palavras-chave: Actividade física, lazer, ginásios, imagem corporal

\begin{abstract}
Reasons for the practice of fitness activities as leisure activities

One of the greatest manifestations in our changing times concerns the gradual decreasing of work time that will lead to a natural free time increasing. Therefore, there's a generalized necessity for fulfilling this free time, and this can be a profit one, if well spared. The goal of our study is to analyse and to find out who are the persons that practice physical activity in their leisure time and choose places like health-clubs or gym academies for it. We intend to perceive the meaning of their choice and why do they continue practicing the kind of physical activities that are offered in health-clubs and gym academies.

Our methodology includes a fieldwork in which we adopted an "insider role" in three gym/health-clubs in the city of Porto, and was supported by a set of semi-structured interviews. After this study, we might consider the person who chooses this kind of physical activity, in its leisure time, as a person who gives a special importance to ones own body image. But, there are other things we must consider, in one hand people should enjoy their practice, in the other hand, they are also looking for connections, relationships that give them reasons to continue, otherwise, they might give up.
\end{abstract}

Key Words: Physical activity, leisure, gym academies, body image 


\section{INTRODUÇÃO}

A nossa sociedade tem sido alvo de contínuas transformações que se fazem sentir fundamentalmente, no tempo, no espaço e no ego, enquanto figuras de excesso (1). Assim sendo, é pela abundância de acontecimentos que se sentem alterações no tempo, quer na sua percepção, quer no uso e modo como dele dispomos, é pela multiplicação de referências imaginadas e imaginárias e pela espectacular aceleração dos meios de comunicação que surgem modificações consideráveis no espaço e é pela pretensão do indivíduo em ser o mundo que se justifica a produção individual de sentido como algo realmente necessário(1). O tempo, enquanto elemento regulador do quotidiano e devido à evolução tecnológica, manifesta-se socialmente cada vez mais como tempo livre e cada vez menos como tempo de trabalho. Este incremento do tempo livre, é, para Baudrillard (3), um tempo "ganho", se ocupado de uma forma útil e se rentabilizado enquanto capital. O indivíduo, social e culturalmente situado, dispõe de uma crescente variedade de ofertas que, inevitavelmente, se sentem no âmbito do tempo livre e do lazer. É nessa diversidade de actividades de lazer que a actividade física surge como uma das formas para "concorrer» com a tecnologização da nossa sociedade (21), emergindo uma cada vez maior variedade de possibilidades para essa prática, no seu âmbito, ou no seu sentido.

Neste contexto de diversidade de oferta da nossa sociedade, também de consumo, denota-se um aumento significativo no número de ginásios, academias e/ou health-clubs, cujo objectivo é corresponder às necessidades evidenciadas na nossa sociedade no que concerne à prática de uma actividade física, que mais do que uma necessidade é, para Crespo (6), uma obsessão do presente que dá importância aos sinais do hedonismo. Um presente que ao ser dominado pela redescoberta do corpo o transformou num dos principais valores do quadro axiológico actual. O presente estudo tem como principal objectivo, analisar, conhecer, saber quem é o aluno/cliente dos ginásios, academias e health-clubs da cidade do Porto, através da percepção do sentido da escolha da actividade e da importância que a esta confere.

\section{TAREFA DESCRITIVA}

Para a concretização da tarefa descritiva, foi desenvolvida uma pesquisa no terreno, recorrendo à observação participante (18) durante os dois últimos anos. Como forma de complementar as informações obtidas nesta pesquisa, realizaram-se 16 entrevistas semiabertas a alunos/clientes (11 do sexo feminino e 6 do sexo masculino, com um intervalo de idades entre os 18 e os 34 anos) de três dos ginásios/academias/health-clubs da cidade do Porto.

As entrevistas foram submetidas à técnica de análise de conteúdo, na medida em que esta permite efectuar inferências sobre as mensagens inventariadas e sistematizadas com base numa lógica explicitada (28). A escolha circunscreveu-se a três destes locais de actividade físical (ginásio $\mathrm{G}$, academia A e health-club $H$ ), na medida em que parecem representar a diversidade de lugares disponíveis para esta prática na cidade em questão (a terminologia utilizada refere-se a três tipos de espaços que se distinguem pela variedade e tipo de serviços que cada um oferece).

Através das conversas informais que se foram estabelecendo ao longo da pesquisa no terreno com os responsáveis destes locais, percebemos que estes lugares se foram ajustando, tentando corresponder às "exigências" da população que pretendiam cativar. Uma população cada vez mais consumista em todos os aspectos da sua vida social e, naturalmente, no tempo dos seus lazeres. Um tempo de consumo que se torna um tempo social forte, assinalado e produtivo de valor, sendo, não uma sobrevivência económica, mas antes uma "salvação social" (3).

É natural, portanto, que os investidores neste tipo de empreendimentos de lazer mais recentes, considerem as orientações do indivíduo enquanto consumidor (21) e prevejam, como principais factores de sucesso a variedade e qualidade de serviços que vendem. Este facto está em consonância com a designada pós-modernidade, de onde subjaz a ideia de que o desporto «investe em si próprio» com elementos do pós-modernismo, no sentido de melhor se constituir como um objecto de consumo desenhado para os cidadãos desta sociedade (22).

\footnotetext{
${ }^{1} \mathrm{Na}$ cidade do Porto existem cerca de 35 ginásios, academias e/ou health-clubs (referimo-nos apenas à cidade e não à sua área metropolitana).
} 
A importância do consumo é realçada com a expressão inconspicuous comsuption, que tem origem, segundo Lipovetksy (15), numa acção convergente de um feixe de valores onde figuram, entre outros, os valores desportivos e o novo ideal individualista do «look» jovem. Valores como o corpo, enquanto imagem "superficial» e capital (9), hedonismo, relativismo e consumismo, adquirem uma valorização cada vez mais «valorada» na sociedade contemporânea ocidental, justificando, por isso, a promoção e o aparecimento deste tipo de investimentos. Esta valorização permitiu, segundo Grande (11), que o corpo tenha uma nova postura no imaginário colectivo da sociedade contemporânea ocidental e urbana que, para uma afirmação pessoal, se desenvolvessem uma série de códigos de tratamento. Efectivamente, podemos integrar as ginásticas de academia como mais uma das técnicas de modelação, manutenção e melhoramento da imagem corporal $(4,29,9,20,14)$.

\section{TAREFA INTERPRETATIVA}

Após efectuarmos uma leitura flutuante sobre o corpus de estudo, a primeira fase da análise de conteúdo definida por Bardin (2), estabelecemos e interrelacionámos como primeira e segunda categorias, as habilitações literárias e a profissão/ocupação, respectivamente, na medida em que geralmente a primeira condiciona a segunda. São estas que nos demonstram, em primeira mão e de um modo geral, as circunstâncias sócio-económicas que prevalecem e influenciam os estilos de vida nos nossos entrevistados. Com efeito, Giddens (9) refere-se ao estilo de vida adoptado como um conjunto de práticas que dão forma a "uma narrativa particular da auto-identidade", práticas essas que fazem parte do quotidiano, da rotina diária, em que o trabalho/emprego está inserido. Se a esfera do trabalho condiciona fortemente as hipóteses de vida, conforme afirma o mesmo autor, este e o ambiente em que se desenrola, não podem separar-se do campo das escolhas plurais, na medida em que se constituem em elementos básicos das orientações dos estilos de vida. Também na concepção de Baudrillard (3), a questão das escolhas está inerente à aceitação do estilo de vida de determinada sociedade e passa pela satisfação das necessidades veiculadas aos valores que prevalecem nessa mesma sociedade. Daí que não se trate tanto de uma escolha, mas antes de uma «reacção" ao consumo enquanto função de integração no grupo e de controlo social, já que este surge, na opinião de Baudrillard (3), "como uma conduta activa e colectiva, como coacção e moral, como instituição". Assim sendo, é natural que a escolha do tipo de actividade física, enquanto uso do tempo de lazer na construção do estilo de vida do indivíduo de determinado grupo social, seja fortemente influenciada pela sua ocupação/profissão (24).

Temos ainda que realçar que, de uma forma geral, o quotidiano do Homem da sociedade contemporânea ocidental e urbana, cada vez mais dispensa o movimento. De facto, até as técnicas mais elementares como correr, andar e saltar foram quase suprimidas, sendo então necessário recorrer, àquilo que Le Breton (14) denomina de próteses técnicas, para aumentar a actividade e dar forma ou "talhar» a sua aparência e/ou incrementar o "seu potencial de saúde». Nesta perspectiva, os aspectos relacionados com o tipo de profissão dos nossos entrevistados não podem ser descurados. Por um lado, porque todos eles têm profissões/ocupações com baixo nível de dispêndio energético, criando-lhes a necessidade de recorrerem a estas "próteses técnicas" e assim minimizarem o carácter hipocinético da sua actividade laboral. Por outro lado, ao terem profissões/ocupações liberais ou ocuparem lugares de quadro superior, a sua capacidade económica permite-lhes praticar uma actividade física num clube privado como o health-club $\mathrm{H}$. Na realidade, tal como referem Laermas (13) e Roberts (24), muitos dos bens e serviços de lazer são de elevado custo económico e, por isso, um salário elevado pode determinar a escolha da actividade física a praticar.

Quando questionados acerca das razões que os levaram a escolher este tipo de actividade física e não outra, a maioria dos nossos entrevistados é omissa quanto à selectividade da actividade, atribuindo a sua prática, essencialmente, à necessidade de "fazer qualquer coisa". Apenas 4 dos 16 entrevistados fundamentam claramente a sua escolha indicando, por um lado, a facilidade de horários relativa à frequência num ginásio/academia/health-club, pois “... o ginásio permite vir sozinho e fazer quando apetece...", por outro lado, a dificuldade inerente às "actividades colectivas, que implicam arranjar um espaço 
diferente o que é mais raro, arranjar um grupo que goste da mesma modalidade que eu, o que também é difícil, arranjar um grupo que tenha disponibilidade de vir praticar quando eu também tenho essa disponibilidade, o que também é difícil...".

A escolha de uma actividade como forma de lazer, também parece estar relacionada com um conjunto de questões que cada um coloca a si próprio acerca de si mesmo. Conforme refere Laermans (13), o indivíduo perante este tipo de decisão questiona-se "quem sou eu?" e nas possibilidades que se colocam, necessariamente, estão subjacentes os objectivos, os desejos e outras questões intimamente ligadas à própria identidade, isto é, "o que é que eu pretendo ser num futuro imediato?" Por conseguinte, existem respostas que demonstram que aliada à necessidade de prática de uma actividade física, está a necessidade de criar hábitos que transformem ou alterem o estilo de vida. Ou seja, "acabei o curso, comecei a trabalhar e comecei a sentir uma grande necessidade de praticar desporto, porque estava a sentir-me muito sedentário, notava que a minha vida era passar o dia todo sentado a trabalhar".

Ao observarmos os dados relativos à idade com que os entrevistados iniciaram este tipo de actividade física, verificámos que são as mulheres que a iniciam mais cedo e que os homens o fazem geralmente após terminarem a sua formação escolar e/ou académica e iniciarem a sua vida laboral. Uma das razões para este facto, está relacionada com a importância que a nossa sociedade atribui à imagem corporal. De acordo com Shilling (25), as mulheres tendem a ser mais encorajadas que os homens a desenvolver os seus corpos como objectos de percepção para os outros. Também Bourdieu (5) considera que as mulheres são inclinadas socialmente a prestarem uma atenção constante a tudo o que se associa à beleza e elegância do corpo. Durante a pesquisa no terreno que fomos realizando nos ginásios em questão, e tal como no estudo efectuado por Maguire e Mansfield (16), percebemos que, de uma forma quase explícita, as jovens e as adultas mais jovens encontram no exercício uma ferramenta para atingir a aparência esbelta e atlética que Lipovetsky (15) e Crespo (7), entre outros autores, sugerem como sendo o estereótipo da mulher na sociedade contemporânea. Por outro lado, o abandono mais tardio de outro tipo de actividades físicas e/ou desportivas por parte dos rapazes, também parece justificar a sua opção por estas actividades numa fase posterior. Efectivamente, os dados obtidos através da nossa observação participante, permitem-nos afirmar que os elementos do sexo masculino procuram este tipo de actividade após esgotadas outras possibilidades no que diz respeito à compatibilidade do horário laboral e à possibilidade de continuar um outro tipo de prática física. A análise do discurso circulante, isto é, das conversas que se desenrolam acerca deste assunto, revela que anteriormente muitos dos sujeitos do sexo masculino tinham outros interesses desportivos, cuja disponibilidade requerida para a sua prática, em função de condicionalismos organizacionais, não se coaduna com o seu actual "dia-a-dia tão ocupado". Quando associamos as razões da escolha desta actividade com as unidades de registo, isto é, com as respostas categorizadas como "Razões para continuar" e "Estar em forma", podemos confirmar a relação existente entre este tipo de actividade física e o conceito de "técnicas do corpo" desenvolvido por Mauss (18). Para este autor, estas técnicas, enquanto hábitos do corpo, modos de agir que são adoptados, desenvolvidos e integrados pela educação e aculturação na sociedade a que se pertence no sentido de adaptar o corpo ao seu uso de um modo eficaz, estão bem demarcadas em cada sociedade, na medida em que têm como função melhorar a eficácia do indivíduo como ser social. Também Ribeiro (23) realça o facto de no uso preciso do corpo estar o resultado da formação social e das técnicas que são diversificadas conforme a imagem ideal de corpo de cada sociedade. Com efeito, as respostas obtidas nas entrevistas e análise do discurso circulante no que concerne à razão pela qual frequentam este tipo de actividades, revelam uma preocupação acrescida com as rotinas de cuidados corporais, entre os quais a prática de ginásticas de academia. Manter a forma, obter uma sensação de bem-estar, estão de facto subjacentes aos objectivos intrínsecos do "culto do corpo", ao culto da melhor imagem corporal. Para a maioria dos entrevistados "Estar em forma", mais do que ter optimizadas as suas capacidades orgânicas e, eventualmente, ter melhorado os seus índices de saúde, é algo que está essencialmente associado à estética corporal, ao "bom aspecto físico", à sensação de bem- 
-estar, é "olhar para o espelho e dizer - Gosto do que vejo!". Parece-nos pois evidente que a prática deste tipo de actividade física está intimamente ligada à importância que o corpo adquiriu no quadro axiológico da sociedade actual, sendo cada vez mais percebido como capital e cartão de visita (10). O corpo ganha mais visibilidade como superfície do que como "algo" que é fundamental manter "funcional e biologicamente eficaz", isto é, o carácter promotor de saúde atribuído à actividade física não parece ter a influência que seria de esperar neste tipo de práticas. A reflexividade inerente à contemporaneidade (9) está tão fortemente imbricada nas atitudes que se adoptam, que se repercute nos hábitos e práticas corporais diárias. Esta interpretação pessoal e repercussão dos valores emergentes da sociedade ocidental contemporânea e urbana, promove a integração de regimes corporais como parte do quotidiano e reitera a importância da actividade física como um «trabalho" que envolve a aparência corporal numa tarefa quase diária. No nosso estudo, este facto é salientado pela categoria Frequência/Tempo de treino. A análise desta categoria sugere que, para os nossos entrevistados, a ida ao ginásio é naturalmente incluída numa rotina diária ponderadamente organizada de forma a contemplar esse fim. Efectivamente, de acordo com Sousa Santos (26), a importância da actividade física enquanto regime corporal e a sua frequência de prática, parece conferir-lhe o estatuto de segunda força produtiva, ao lado daquela que é considerada a primeira força de trabalho propriamente dita.

Ao questionarmos os indivíduos sobre a relevância da ida às aulas de ginástica, relativamente a outras tarefas diárias, as suas respostas sugerem um elevado grau de prioridade concedido à "construção" da aparência corporal, pois “...tudo o que marco tento que não seja à hora da ginástica”, "sim, deixo de fazer algumas coisas".

O confronto da análise da frequência e tempo de permanência no ginásio com as restantes categorias, assim como a informação adquirida através da pesquisa no terreno, revelam a existência de outros factores para além dos intrínsecos à condição de aluno/cliente de um ginásio/academia/health-club, isto é, extrínsecos à prática da actividade física propriamente dita, que parecem igualmente influenciar a sua assiduidade a estes locais de culto do corpo. É notório que a frequência e o tempo de permanência aumentam de acordo com o nível de ligação afectiva estabelecida entre os "companheiros» de actividade. Este facto parece conjugar o processo de individualização e as possibilidades sociais que Laermans (13) tão bem expressa ao afirmar que "along with the process of "self production" a lot of "social production» occurs". Frequentemente, alguns dos alunos clientes deslocam-se ao ginásio sem qualquer outro motivo que não seja "...hoje só passei por cá para ver quem estava", pois como referem Henderson e Frelke (12) "people are looking for connections". Com efeito, a análise da categoria relacionada com as razões para continuar a actividade em análise, sugere existir uma noção de identidade associada ao lugar que Henderson e Frelke (12) mencionam como significante na configuração do ambiente humano. $\mathrm{O}$ espaço, este não é estático, pelo contrário, é dinâmico e, neste caso concreto, criado por uma série de inter-relações sociais derivadas de todo um conjunto de actividades que se desenrolam e que lhe conferem um estatuto de existencialidade para uma identidade. "A tal ponto que se pode falar de um espaço mental" (19), cuja geografia se esbate na experiência individual e colectiva, projectando-se na construção identitária e imaginária do indivíduo.

Esta necessidade de identificação com o espaço resulta, ainda, na promoção e oferta de outro tipo de actividades organizadas para os alunos/clientes e paralelas àquelas regulares nestes centros de lazer (torneios de squash, actividades de aventura ou jantares inerentes à época festiva), para que assim não se criem rotinas no lazer, pois, tal como Elias e Dunning (8) afirmam, se estas se instalam e não houver mais nada de novo nas actividades de lazer, esvaziam-se de qualquer função.

Relativamente aos tipos de aulas pelos quais os alunos podem optar, os nossos dados indicam que é nas denominadas ginásticas localizadas ${ }^{2}$ que estão as suas principais preferências, seguidas pelas aulas de

\footnotetext{
${ }^{2}$ Nesta denominação incluem-se uma grande variedade de actividades cujo objectivo é desenvolver uma aula onde os exercícios propostos são focalizados em determinados grupos musculares, de que são exemplo as aulas de localizada, abdominais, glúteos, bodypump, pushpower, gap.
} 
step $^{3}$ e pelas de spinning 4 e musculação ${ }^{5}$. Na realidade, é nas ginásticas localizadas que a "tarefa" de "tonificar os músculos", como referem, é mais percebida como necessária e o esforço aliado ao sofrimento são sentidos com mais intensidade, isto é, como "tem que ser", "faz parte", pois essa parece ser a via mais eficaz para conseguir o corpo "trabalhado", o corpo desejável (27) e assim melhor corresponder ao estereótipo feminino da sociedade contemporânea. Markula (17), num estudo similar ao nosso, afirma que os exercícios que se realizam neste tipo de aula são planeados e configurados para melhorar a aparência corporal e, mesmo que considerados "tortuosos, difíceis e horríveis", são entendidos pelas alunas como imprescindíveis para atingir o "tónus muscular", tão desejado e socialmente reconhecido e apreciado. De certa forma, este facto está em consonância com o que Shilling (25) afirma relativamente às técnicas corporais, já que estas, embora habilitadoras, são simultaneamente constrangedoras e ofensivas, pelo "sacrifício» que podem envolver.

Relativamente às aulas de step e de spinning, embora ambas se possam enquadrar conjuntamente quanto à preponderância da solicitação energética a que fazem apelo e, consequentemente, associar aos objectivos inerentes às alterações da composição corporal, nomeadamente a perda de massa gorda, parecem, contudo, distinguir-se pela existência de uma componente coreográfica que está presente no step e ausente no spinning. Decorrente da participação mais isolada de determinados grupos musculares no movimento padrão do spinning, isto é, no movimento de pedalar, esta actividade é ainda distinguida do step, pelos participantes, quanto à percepção subjectiva de esforço. A opção pelas aulas de spinning, relativamente ao step, está por isso associada aos alunos/clientes que procuram uma actividade menos coreografada, mas sentida como mais intensa e, assim, potencialmente mais adequada ao objectivo e

\footnotetext{
${ }^{3}$ Actividade desenvolvida com movimentos baseados na marcha e que consiste em subir uma plataforma, concebida para o efeito, acompanhada de música.

${ }^{4}$ Actividade realizada em bicicleta estacionária que se baseia no movimento de pedalar em diferentes posições, acompanhada de música cujo ritmo define a intensidade do esforço a adoptar.

${ }^{5}$ Actividade que recorre a máquinas, pesos livres e outros materiais para o desenvolvimento da força muscular.
}

"necessidade de emagrecer", pensando que por ser "nestas aulas que se transpira" e "sinto que gasto mais energia", conseguirão atingir a sua meta.

\section{CONCLUSÃO}

A análise dos resultados do nosso estudo sugerem que o cliente do ginásio/academia/health-club da cidade do Porto opta por este tipo de actividade, não só pela necessidade de prática de actividade física mas, igualmente, por considerar esta "técnica corporal" como um instrumento que lhe permite corresponder aos parâmetros estético-corporais "impostos" pela sociedade contemporânea ocidental e urbana. Adicionalmente, na opinião dos nossos entrevistados, parece ser a prática destas actividades físicas nestes locais de culto do corpo, em função das disponibilidades e ofertas logísticas existentes, as que mais se adequam e compatibilizam com as dificuldades inerentes aos horários e constrangimentos laborais. "Sentir-me bem comigo próprio", é uma das principais razões apontadas para que o cliente continue a prática destas actividades, porém, a frequência com que se deslocam a estes locais também depende, a par dos objectivos intrínsecos à prática de uma actividade física, do tipo de relações sociais que aí se vão desenvolvendo. Assim, quanto mais ligado afectivamente, mais frequentemente aí se desloca e permanece.

De uma forma geral, a escolha da actividade a desenvolver nestes locais, de entre um vasto leque de possibilidades e ofertas, parece estar mais associada a preocupações de ordem estética e à imagem corporal do que aos aspectos inerentes à diminuição de factores de risco no âmbito da saúde.

\section{CORRESPONDÊNCIA}

\section{Ana Luísa Pereira}

Faculdade de Ciências do Desporto

e de Educação Física

Universidade do Porto, Portugal

Rua Dr. Plácido Costa, n. ${ }^{\circ} 91$

4200-450

analp@fcdef.up.pt 


\section{REFERÊNCIAS}

1. Augé M (1996). Los «no lugares» - Espacios del anonimato: Una antropologia de la sobremodernidad. Barcelona: Gedisa Editorial

2. Bardin L (1995). Análise de conteúdo. Lisboa: Edições 70

3. Baudrillard J (1995). A sociedade de Consumo. Lisboa: Edições 70

4. Bordo S (1998). Bringing body to the cry. In Don Helton Cornwall (Ed). Body and flesh-A philosophical reader. London: Blackwell Publishers, 45-59

5. Bourdieu P (1999). A dominação masculina. Oeiras: Celta Editora

6. Crespo J (1990). História do Corpo. Lisboa: Difel

7. Crespo J (1997). O corpo na sociedade actual. In: Anatomias Contemporâneas - O corpo na Arte Portuguesa dos Anos 90Catálogo. Oeiras: Câmara Municipal de Oeiras, 14-18

8. Elias N, Dunning E (1992). A Busca da Excitação. Lisboa: Difel

9. Giddens A (1994). Modernidade e identidade pessoal. Celta Editora: Lisboa

10. Giddens A (1997). Sociology. Cambridge: Polity Press

11. Grande N (1997). O corpo no fim do século. In: Anatomias Contemporâneas - O corpo na Arte Portuguesa dos Anos 90Catálogo. Oeiras: Câmara Municipal de Oeiras: 19-22

12. Henderson K, Frelke C (2000). Space as vital dimension of leisure: the creation of place. World Leisure Journal (42) 3 : $18-24$

13. Laermans R (1992). Leisure as a making time. In: Actas do Congresso Mundial do Lazer. Lisboa: Edições do Instituto de Ciências Sociais da Universidade de Lisboa: 61-73

14. Le Breton D (1999). L'Adieu au corps. Paris: Éditions Métailié

15. Lipovetsky G (1989). O Império do efémero - a moda e o seu destino nas sociedades modernas. Lisboa: Publicações Dom Quixote

16. Maguire J, Mansfield L (1998) No - Body's Perfect: Women, Aerobics, and the body beautiful. Sociology of Sport Journal 15: 109-137

17. Markula P (1995). Firm but shapely, fit but sexy, strong but thin: the postmodern aerobicizing female bodies. In: Andrew Yiannakis, Merril Melnick (ed.) Contemporary Issues in Sociology of Sport. Champaign: Human Kinetics: 237-257

18. Mauss M (1989). Sociologie et Anthropologie. Paris: Presses Universitaires de France

19. Merleau-Ponty M (1996). Fenomenologia da Percepção. São Paulo: Martins Fontes

20. Morgan K (1998). Sculpted bodies- women and the knife: cosmetic surgery and the colonization of women's bodies. In: Don Helton Cornwall, Blackwell (Ed.). Body and flesh- $A$ philosophical reader. London: Blackwell Publishers: 325-347

21. Mota J (1997). A actividade física no lazer - reflexóes sobre a sua prática. Lisboa: Livros Horizonte

22. Rail G (1998). Seismography of the postmodern condition: three theses on the implosion of sport. In: Geniève Rail (Ed) Sport and Postmodern Times. Albany: State University of New York Press: 143-161

23. Ribeiro A (1997). Corpo a corpo - Possibilidades e limites da crítica. Lisboa: Edições Cosmos

24. Roberts K (1995). Work and its corollaries. In: C Critcher, P Branhau, A Tomlinson (Eds.) Sociology of Leisure - a reader. London: E. \& FN SPON: 38-42
25. Shilling C (1993). The body and social theory. London: Sage Publications

26. Sousa Santos B (1996). Pela mão de Alice. Porto: Edições Afrontamento ( $5^{\mathrm{a}}$ ed.)

27. Turner B (1996). The body and society. London: Sage Publications

28. Vala J (1986). A análise de conteúdo. In: Augusto Santos Silva, José Madureira Pinto (org) Metodologia das Ciências Sociais. Porto: Edições Afrontamento: 101-128

29. Wolf N. (1991). O Mito da beleza. Lisboa: Círculo de Leitores. 